\title{
Inspection system for very thin and fragile surfaces, based on a pair of wall climbing robots with magnetic wheels
}

\section{Conference Paper}

Author(s):

Fischer, W.; Tache, F.; Siegwart, R.

Publication date:

2007

Permanent link:

https://doi.org/10.3929/ethz-a-010038359

Rights / license:

In Copyright - Non-Commercial Use Permitted

Originally published in:

https://doi.org/10.1109/IROS.2007.4399060 


\title{
Inspection System for Very Thin and Fragile Surfaces, Based on a Pair of Wall Climbing Robots with Magnetic Wheels
}

\author{
W. Fischer, F. Tâche, and R. Siegwart
}

\begin{abstract}
- this paper describes a pair of wall climbing robots that use magnetic wheels for adhesion. They are designed for inspecting the interior surfaces of gas-tanks in oversea ships. Environments like this were impossible to access by previous climbing robots, as they are made out of very thin sheet metal that cannot support a high robot mass and contain several types of difficult obstacles.
\end{abstract}

In order to master these challenges, the system described in this work uses two robots in a "mother-child"-structure: The smaller robot is built very lightweight and simple, without the ability to steer or climb vertically. It just moves horizontally and uses ridges in the gas tank surface as guidance rails. In order to pass from one ridge to the next one, the smaller robot docks to the bigger "mother"-robot. This robot always stays in an area where the sheet metal is thicker and never enters the extremely fragile surfaces. Thus, its mass is not critical for the structural stability of the environment and the robot can hence be built big enough to be able to climb in all directions of gravity and to pass difficult obstacles along its path.

In the present paper, the basic concept, the mechanical design of all important components and the proposed control strategy are described briefly, followed by test results of the most critical components. An outlook to similar applications to which the basic idea of this work can be successfully transferred concludes this article.

Keywords - Cooperating Robots; Field Robots; Mechanism Design; Robotics in Hazardous Fields; Service Robots; Wheeled Robots

\section{INTRODUCTION}

G AS-TANKS made out of thin sheet metal are installed in oversea ships that are used for the transportation of liquid gas. Periodically, these tanks have to be inspected for detecting leaks, especially along the welds. For this purpose, helium is injected in the structure that surrounds the tanks. A sensor that is able to detect helium leaking into the tank is used to determine the position of leaks. Currently, this sensor is carried by a balloon that is operated manually with the use of long ropes. As this method is very slow and

Manuscript received March 27, 2007. This work was done at the Autonomous Systems Lab within the Institute of Robotics and Intelligent Systems at ETH Zürich. It was supported by GAZTRANSPORT \& TECHNIGAZ, 1, route de Versailles, 78470 Saint-Rémy-lès-Chevreuse, FRANCE under A. Charoy and A. Mangé.

W. Fischer is a PHD student at ETH Zürich, Tannenstrasse 3, CLA E 18, CH-8092 Zürich, Switzerland (phone: +41-44-632-2740; fax: +41 44632 1181 ; e-mail: wfischer@ethz.ch).

F. Tâche is a PHD student at ETH Zürich (phone: +41-44-632-8905; e-mail: ftache@ethz.ch)

R. Siegwart holds the professorship at the Autonomous Systems Lab the at ETH Zürich (phone: +41-44-632-2358; e-mail: rsiegwart@ethz.ch) imprecise, a better inspection system had to be developed, preferably using specialized wall climbing robots with magnetic wheels.

In this paper, we describe a novel system for this kind of application, which consists of a huge wall-climbing robot with high mobility (mother) for climbing and passing obstacles and a second, small and simple one (child) that is carrying the detector. This second robot is only able to drive horizontally along the welds on the thin metal sheets and is carried from weld to weld by the big mother robot. For passing ridges (next to the welds) and other obstacles, the mother robot uses an optimized version of the locomotion system described in a previously published paper [1].

The paper is structured as follows: Chapter II introduces the current state of the art, focusing not only on other wall climbing robots, but also on obstacle passing mechanisms and mother child structures. Chapter III describes the details of the application and explains the limits of using just a single climbing robot like the one described in [1]. The advantages of using a mother-child-structure are pointed out in IV and the most important details of the design exposed in chapter V. Chapter VI shows the results of actual tests in simulated environments and calculations of the most critical components. The conclusion in the last chapter focuses on the main innovative ideas and the adaptation of the presented system to similar applications.

\section{STATE OF THE ART}

The system described here consists of a pair of wall climbing robots in a "mother-child" structure, with advanced obstacle-passing capabilities implemented in the bigger one. This chapter is divided into the three fields of technology that are used in this system: wall climbing robots, structures for passing obstacles, and mother child structures.

\section{A. Wall climbing robots}

Mobile wall climbing robots are used in various applications - not only for non-destructive testing, but also for cleaning, repairing, transportation, and other tasks. The two main characteristics within these robots are the adhesion mechanism and the locomotion principle. According to [2], the most common adhesion mechanisms are magnetism [3][12], vacuum suction [13]-[15], and specific attachment devices such as rails [16] or pegs and grippers/clamps [17]. Current research is also done in exploiting other adhesion principles such as patterned elastomers, hairy structures [18] or arrays of micro spines [19]. The obtained adhesion force 
is not very high in comparison to the other principles, but also works on porous and non-ferromagnetic surfaces.

Locomotion can be either achieved with wheels [3]-[7], tracks [11], legs [9], arms or a combination of these principles [1], [8], and [15]. As the robots presented in this work use magnetic wheels, the following descriptions primarily stress on this class of wall climbing robots.

A very simple structure for a climbing robot is a vehicle on two (like the "Magnebots" [3]) or more magnetic wheels. Such vehicles mainly use wheels similar to the one described in U.S. Patent 3,690,393 [4]. These wheels increase the normal force to the metallic surface and allow the robot motion to be more independent from the direction of gravity. As the required torque for climbing vertically is much higher than for robots which only move horizontally, the actuators need to be considerably stronger. To temporarily overcome the adhesion forces and to facilitate passing angular transitions the wheels are sometimes equipped with special mechanisms that and can either be passive [6] or active [7].

\section{B. Magnetic wheeled robots that can pass difficult obstacles (ridge-type)}

For passing even more difficult obstacles, some of these robots are equipped with special mechanisms within their structure. The "Pipe Inspection Robot (PIR) Type III" [8], for example, uses 3 pairs of wheels that can be lifted with linear actuators in order to pass obstacles on the outside surfaces of pipes. A robot designed for gas-tanks with sheet thickness of $1.5 \mathrm{~mm}$ everywhere is described in [1]. This robot also uses linear movements, but needs fewer actuators than the PIR and is optimized for thin surfaces with limited magnetic attraction. Fig. 1 shows how this robot passes a ridge type obstacle. Its mass is around $10 \mathrm{~kg}$.
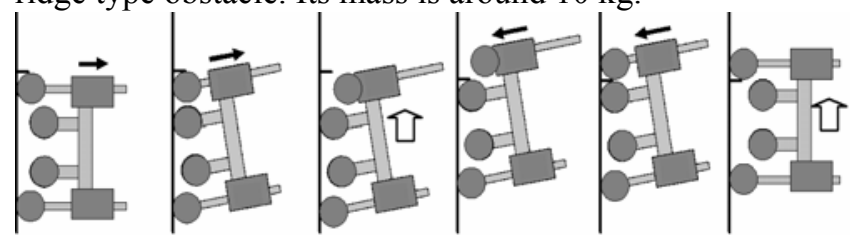

Fig. 1: Active obstacle passing mechanism in a magnetic wheeled wall climbing robot for thin surfaces [1]

\section{Mother-child structures / docking:}

Transporting a small vehicle for narrow and/or fragile environments in a huge one is a common practice both in high-tech robotics (field robot carried in a spaceship) as well as in everyday life (bicycle transported in a train). In wall climbing robots, this principle has not been used frequently, even if it can bring advantages in narrow or fragile environments.

The existing systems that are least related to our concept are the "Anchor Climber" for inspecting ship hulls [12] and the "MATS"-robot for helping disabled people [20]. While in the "Anchor Climber" the "child" robot is just guided by ropes that are attached to both of the parent robots ("anchors"), the MATS robot moves autonomously between different docking stations that are installed in the domestic environment and on the user's wheelchair.

\section{APPLICATION AND REQUIREMENTS}

The goal is to develop an inspection system that can carry a sensor module (approximate mass: $0.3 \mathrm{~kg}$ ) to every point of the interior hull of a gas tank (Fig. 2). The robot must therefore be able to move vertically as well as upside down suspended from the ceiling. It must be able to pass obstacles in the form of ridges and $135^{\circ}$-transitions and must be built light enough to not destroy the fragile structure of the tank.

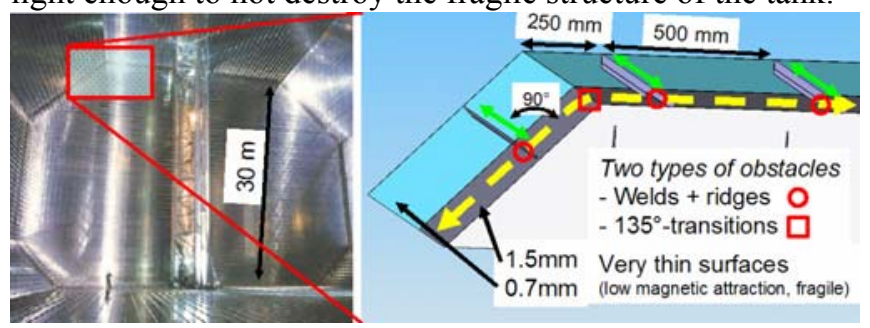

Fig. 2: The environment to inspect

\section{A. Obstacles (ridges and $135^{\circ}$-transitions)}

The main obstacles are ridges and $135^{\circ}$-transitions (Fig. 3, dashed line). On top of the ridges (the worst obstacles) the magnetic attraction gets reduced to $1 / 7$ of the normal value. To pass them with a wheeled robot, a structure similar to the one described in [1] and Fig. 1 is necessary. For ridges up to $4 \mathrm{~mm}$ height, $1.5 \mathrm{~mm}$ of sheet thickness and an assumed maximum friction coefficient of $\mu=0.5$, the resulting robot would weigh around $10 \mathrm{~kg}$.

In all tanks, the ridges are perpendicular to the next wall.

\section{B. Fragile structure in the center}

Often, the central area of these tanks (Fig. 2, light area) consists of very thin $(0.7 \mathrm{~mm}$ instead of $1.5 \mathrm{~mm})$ sheet metal, which is only attached at the ridges. Thus, a huge and heavy robot would plastically deform and damage the structure. Apart from this, it might even slip and fall down, as the thin sheets cannot provide sufficient magnetic force due to magnetic saturation.

FEM simulations and tests in the environment showed, that sheets of this thickness $(0.7 \mathrm{~mm})$ can only support a mass of $5 \mathrm{~kg}$ - half the one of the robot described in [1].

\section{Need for higher speeds}

In order to keep the total inspection time low, another important goal was to achieve higher speeds. As mentioned earlier, the torque required for climbing vertical is very high. Hence, a robot as described in [1] needs to use huge reductions in the transmission between motors and wheels if light and small DC-motors are used. This limits the velocity when driving horizontally. Using different actuators for vertical climbing and horizontal driving could hence improve the overall performance.

\section{BASIC CONCEPT AND ITS ADVANTAGES}

As pointed out in the previous section, the use of a single 
robot that is able to go everywhere in the tank does not provide a satisfactory solution. Even if all parts were optimally designed, a structure able to pass all obstacles would be so heavy that it could damage the fragile surfaces in the center of the tank. Additionally, such a single robot would be very slow. This lead to the idea of separating the inspection system into two robots with specialized tasks.

The smaller of these two robots is built very simple and without the ability to climb. It just moves along horizontal paths and uses the ridges in the structure as a guidance rail. Due to its low mass can pass the fragile surfaces without causing problems. In order to pass to the next ridge, it docks at the bigger robot. This robot always stays on the thick sheets $(1.5 \mathrm{~mm})$ near the rims. Its mass is less critical and the robot can hence be built complex enough to be able to climb and pass obstacles.

$\frac{1 \mathrm{DOF}, 2 \mathrm{~kg} \text {, fast many DOF, } 15-20 \mathrm{~kg} \text {, slow }}{\stackrel{\text { child }}{\longrightarrow} \text { mother robot }}$

Fig. 3: Basic idea for the new concept - separation into two robots

Another advantage of this system is that the child robot can be built very fast. As the robot is light weight and only moves horizontal, the required torque is very low. Thus, a fast actuator with low reduction gear can be chosen.

\section{DeTAILED DESIGN OF THE MAIN COMPONENTS}

The main work packages concerning the design were to design both robots in detail and to realize a robust control.

\section{A. Mother robot-weight-minimized design}

The mother robot is built very similar to the robot described in [1], consisting of 4 motorized wheel units and 2 linear actuators. Such a structure is able to pass ridge-type obstacles by consecutively lifting its wheels (Fig. 1).

In contrast to the robot described in [1], the newly designed mother robot does not need to turn on spot, which allows building it lighter. The steering motors were hence removed. Slight steering corrections are done by driving with different motor speeds on each side.

This design has the additional advantage that the wheel unit's width can be increased. Tests showed, that a better ratio between magnetic force and mass $(\mathrm{Fmag} / \mathrm{m})$ could be achieved with wheels that have a larger inner diameter. Five of these wheels have less mass but provide a higher magnetic force than the two wheels used in the old design.

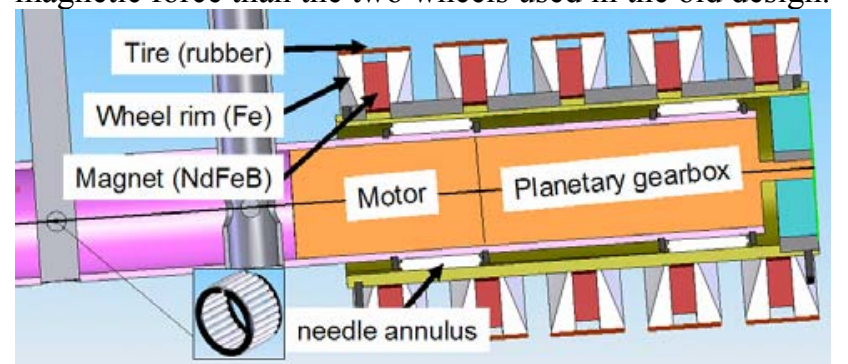

Fig. 4: Wheel unit in the mother robot
To optimally use the given space (Fig. 4), the actuators (DC motors with planetary gearboxes) are placed inside the wheels. All wheel rims are shaped conically to save mass without decreasing the magnetic force. They are covered with a thin tire (rubber, $0.6 \mathrm{~mm}$ ), which increases the friction coefficient to the surface from $\mu=0.2-0.3$ to $\mu=0.5-0.8$ and thus significantly decreases the risk of slipping.

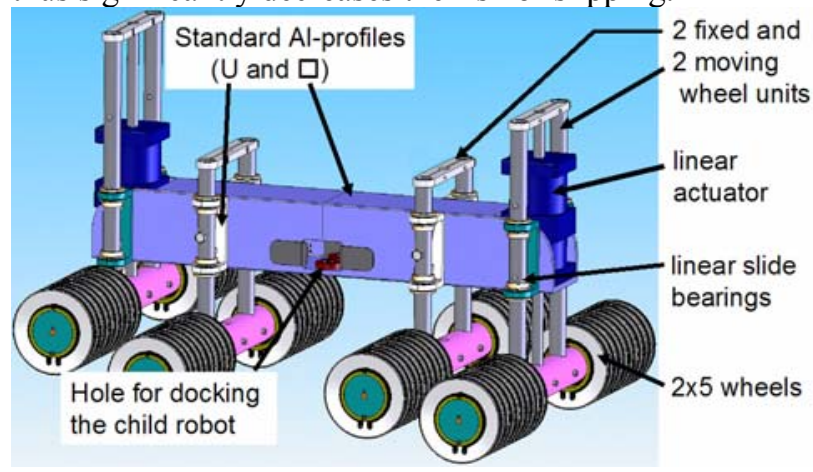

Fig. 5: Overall structure of the mother robot

Linear actuators with ball screw spindles and stepper motors are used to lift the wheels when passing obstacles (Fig. 1). These actuators have to deal with less friction than the ones with trapezoidal spindles and thus allow forces up to $800 \mathrm{~N}$ at a mass of only $600 \mathrm{~g}$. The linear guidance is done by 2 tubes that are mounted in linear slide bearings. The remaining structural parts are made of standard $U$ and rectangular profiles to obtain the necessary structural stability at a reasonable manufacturing cost (Fig. 5).

\section{B. Child robot and docking}

As mentioned earlier, the child robot has a very simple design. It consists of one single motor and a pure mechanical guidance along the ridges (Fig. 6). As connection to the mother robot, it uses a hook made out of magnetic steel that can be temporarily attached to a pair of magnets in the mother robot.

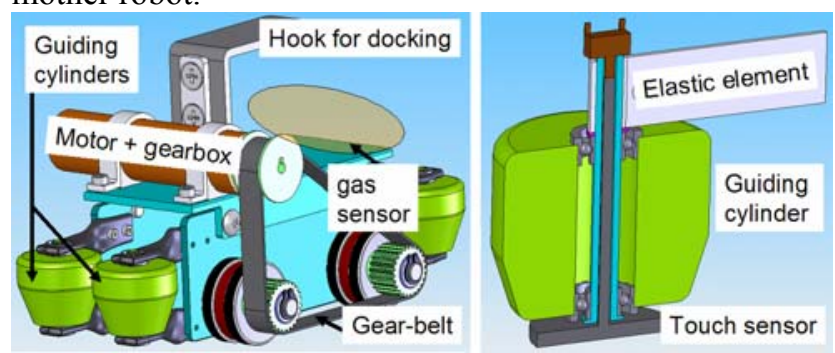

Fig. 6: Child robot - simple structure using a pure mechanical guidance

To release the child robot, the mother robot uses its linear actuators to move until this magnetic contact is opened and the child robot is free. Touch sensors are used to make sure that the mother robot is at the correct position, when releasing or collecting the child robot. The touch sensors on the mother robot are placed near the docking hole (Fig. 7), the ones on the child robot within the guidance cylinders (Fig. 6, right).

A gear-belt connection is used to transmit the motor torque to the wheels. The guidance is made out of 4 cylinders. Each is suspended by two small ball-bearings and pressed against the ridge by springs. This structure has very low friction and can adapt to ridges with varying thickness. 
As the magnetic force can be considerably lower than in the mother robot (no vertical motion, smaller mass), the wheels of the child robot are smaller ( $D=30 \mathrm{~mm}$ instead of $60 \mathrm{~mm}$ ). They are also conically shaped and covered with a thin rubber tire.

\section{Sensors and control strategy}

As the environment is structured uniformly and consists out of very few, repeating elements, a nearly autonomous control strategy can be realized for both, the child and the mother robot. Three types of sensors are used to obtain the necessary inputs for the controller:

- Encoders in all motors

- Touch less distance sensors (ultrasonic or radar)

- Binary touch sensors

The control strategy involves four main tasks: moving the child robot, moving the mother robot, releasing the child robot and collecting it in again.

For less uniformly structured environments, the mother robot can also be remote controlled. To facilitate this, a camera should be placed on top of the structure to better see the ridges and the child robot.

1) Moving the child robot

As the child robot is guided mechanically along the ridges, only one DOF has to be controlled. This motion is controlled using the sensor input of the encoder on the motor and touch less distance sensors on both sides that measure the distance to the end wall.

\section{2) Moving the mother robot}

Due to the obstacles, it is not possible to guide the mother robot purely mechanically, for example along a wall. In order to keep a straight path, the robot uses two ultrasonic distance sensors that point perpendicular to the direction of motion and measure the distance and the relative angle to the next wall. This information is used to adjust the speed in the wheels on each side of the robot and thereby correct the path. These corrections are so small that the slightly elastic structure of the robot is sufficient and no extra DOF is needed.
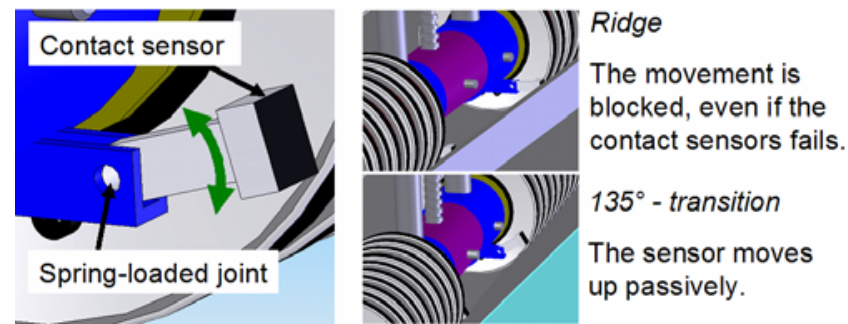

Fig. 7: Structure holding the contact sensor that detects the ridges

In order to know when to lift the wheels to pass the ridges, all wheel units are equipped with touch sensors on both sides that are fixed on a spring-loaded joint (Fig. 7). This design mechanically blocks the robot when approaching the ridges, but moves up passively when passing $135^{\circ}$ transitions. This ensures that the robot is always safe against rolling onto the ridges (where it could loose its magnetic adhesion) even if the sensors fail. The sensors do not obstruct the motion when passing the $135^{\circ}$ transitions
When a contact is detected, the linear actuator is used to lift the wheel to its upper position. Then, the robot moves forward until the ridge is passed and the wheel is placed again on the surface. The whole sequence of passing the ridges is similar to the one described in [1] and Fig. 1.

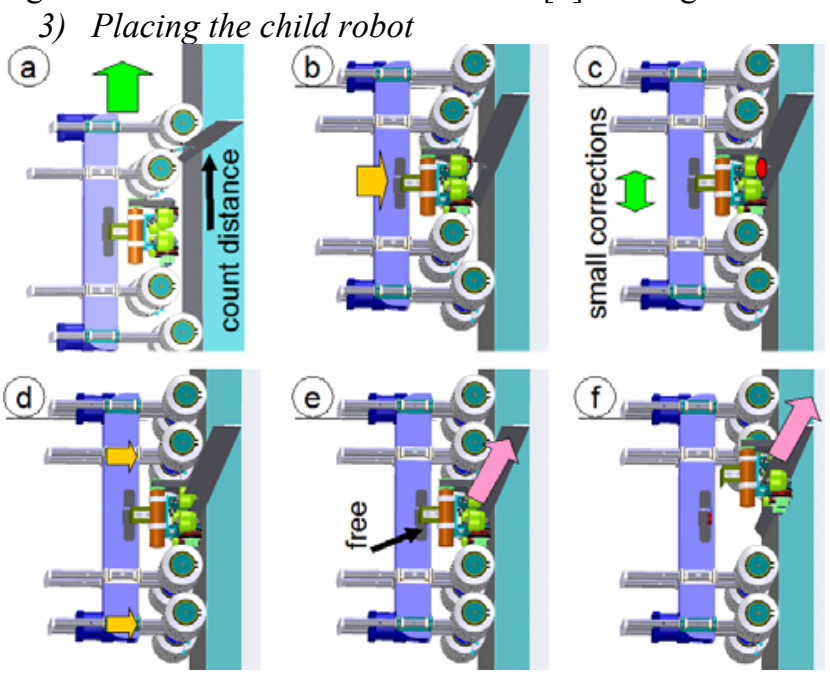

Fig. 8: Placing the child robot on the ridge

To place the child robot on a ridge, both linear actuators move down simultaneously (Fig. 8). To roughly determine the correct position, the distance corresponding to half the robot's length is counted with the wheel motor's encoders starting from the end of last the obstacle-passing sequence). The accurate positioning is determined by the touch sensors on the child robot (Fig. 8.c) when the robot is already close to the ridge. The height of the magnetic hook on the child robot is chosen such that the child robot touches the surface approximately $1 \mathrm{~cm}$ before the mother robot's middle wheels do (Fig. 8.d). This allows releasing and collecting the robot without using an extra actuator.

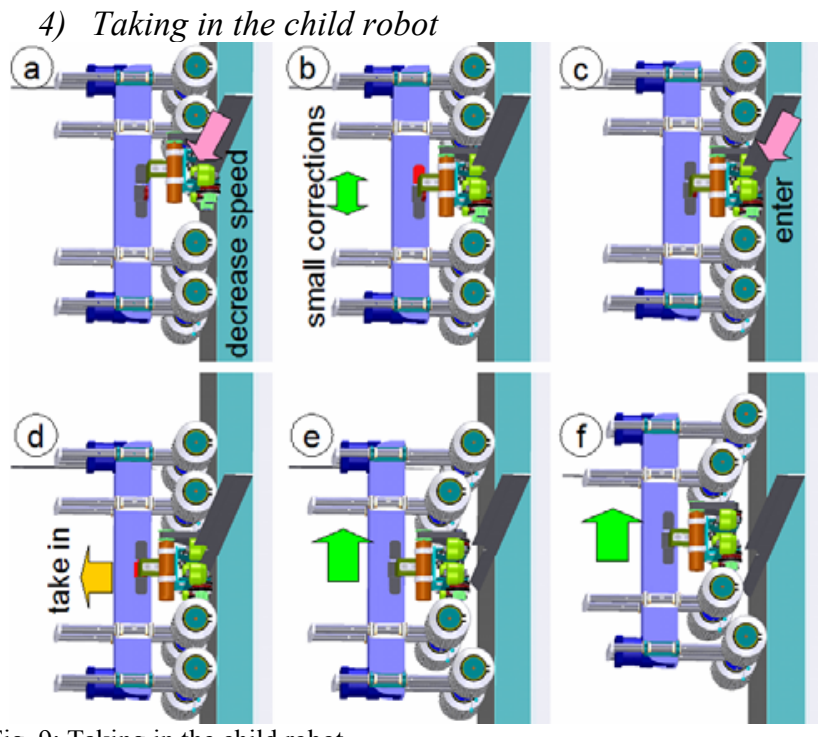

Fig. 9: Taking in the child robot

The child robot's distance to the mother robot is estimated from the wheel encoders and the ultrasonic distance sensors. The mother robot's relative position can be detected by touch sensors near the docking hole (Fig. 5) and corrected if 
necessary (Fig. 9.b). When the hook on the child robot touches the back of the docking hole, the linear actuators are activated (Fig. 9.d) and lift the child robot from the surfaces. It is ready to be moved to the next ridge.

\section{FIRST RESUltS}

The most critical components have already been tested and validated to proof the usability of the general concept.

\section{A. Wheel unit}

To verify the mechanical properties of the wheels and to do deformation test on the environment, a prototype of one wheel unit was manufactured (Fig. 10).

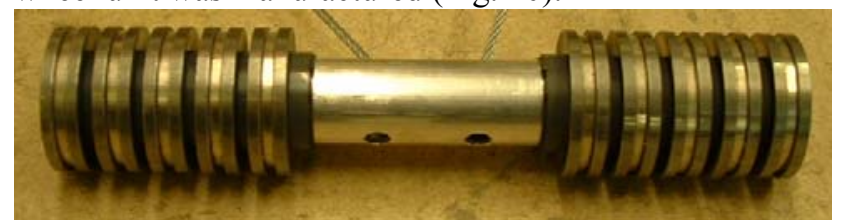

Fig. 10: Wheel unit for testing

With 10 wheels in parallel we could achieve a magnetic force of $580 \mathrm{~N}$ (on $1.5 \mathrm{~mm}$ sheet metal, tire $0.6 \mathrm{~mm}$ thick). This value is slightly below the force that 10 independent wheels would provide $(10 * 70=700 \mathrm{~N})$. This decrease in force is due to saturation effects from the neighboring wheels. Increasing the gap between the wheels would lead to higher forces, but increases the necessary space and weight. Within the possible dimensions $(350 \mathrm{~mm})$, a choice of wheel numbers $(6,8,10$ or 12 wheels; gap 0 to $25 \mathrm{~mm})$ were tested. The best results were achieved with a unit consisting of 10 wheels and a gap of $5 \mathrm{~mm}$ between the wheels.

The magnetic wheels $(0.15 \mathrm{~kg} * 10=1.5 \mathrm{~kg})$ are the biggest factor in the $2.5 \mathrm{Kg}$ overall mass of the unit. The two actuators are $0.2 \mathrm{~kg}$ each, structural components constitute $0.6 \mathrm{~kg}$.

The two actuators provide an intermittent torque of $\mathrm{T}=2 * 3000 \mathrm{mNm}$. This, and a wheel radius $\mathrm{r}=30 \mathrm{~mm}$, leads to a possible traction force $\mathrm{F}_{\mathrm{t}}=200 \mathrm{~N}$.

\section{B. The entire mother robot}

With these values being known, the mechanical properties of the whole mother robot could be verified and its functionality proven.

1) Mass, impact on the environment, linear actuators

The robot's mass is around $\mathrm{m}=18 \mathrm{~kg}$ and composed mainly of the 4 wheel units $(2.5 \mathrm{~kg}$ each). The remaining 4 main components (structure with linear actuators, child robot, electronics and cable) are all around $2 \mathrm{~kg}$ each. This leads to a gravity force of $\mathrm{G}=180 \mathrm{~N}$ approximately. However, the biggest impact on the environment will not come from this gravity force, but from the magnetic force $\left(F_{m a g}=580 \mathrm{~N}\right)$ when lifting and lowering the wheels in order to pass the ridges. As verified in experiments on a real gas tank, this force does not damage the environment. The linear actuators are also able to provide a force of this magnitude.
2) Risk of slipping and damaging the wheel actuators

In order to estimate the risks of slipping and damaging the wheel actuators, two scenarios were analyzed: climbing a vertical wall and getting away from the $135^{\circ}$-transitons.
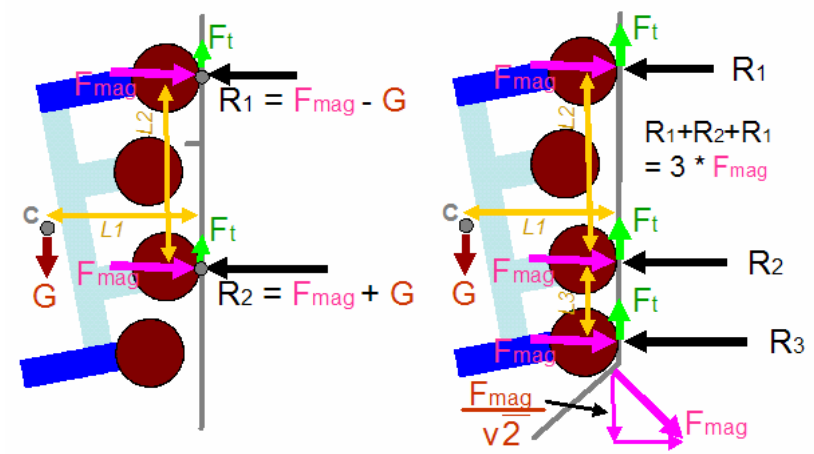

Fig. 11: Critical forces when climbing and passing $135^{\circ}$-transitions

In the case of "normal" climbing (Fig. 11, left), two wheel units are in contact with the surface. Estimating similar torque in all actuators, the necessary traction force per wheel unit results to $\mathrm{F}_{t}=90 \mathrm{~N}\left(\mathrm{~m}^{*} \mathrm{~g} / 2\right)$. This is significantly below the value the actuators can provide $(200 \mathrm{~N})$. Estimating the distance between center of mass (C) and environment ( $L 1)$ approximately the same as the distance between both wheels (L2), the reaction force on the upper wheel results to be $\mathrm{R}_{1}=\mathrm{Fmag}_{\mathrm{g}} \mathrm{G}$ (torque equilibrium at the lower contact point). With these values, the required friction coefficient there results to be around $\mu=0.19\left[=\mathrm{F}_{\mathrm{t}} / \mathrm{R}_{1}=75 /(580-180)\right]$, and thus still stays significantly below the measured one $(\mu=0.5-0.8)$.

The actual worst case is when getting away from the $135^{\circ}$-transitions (Fig. 12, right). At this moment, the robot does not only have to support its own mass, but also has to detach its last wheel from the old surface, where it still sticks on. An additional vertical force of $410 \mathrm{~N}(=580 \mathrm{~N} / \sqrt{2})$ results. Together with gravity, the total force in vertical direction is $\mathrm{F}_{\mathrm{t}, \mathrm{total}}=590 \mathrm{~N}(=410 \mathrm{~N}+180 \mathrm{~N})$. It is possible to create this force with the robot, but only if at least 3 wheels are in contact with the surface and if all of them provide full traction $(3 * 200 \mathrm{~N}>590 \mathrm{~N})$. All reaction forces together are $3 * F_{m a g}$ and their repartition can be regulated with the linear actuator in the structure. With the current geometry $(\mathrm{L} 1=\mathrm{L} 2=2 * \mathrm{~L} 3)$, an optimum for maximizing the lowest $\mathrm{R}$ can be found with $\mathrm{R}_{1}=\mathrm{R}_{2}=\mathrm{Fmag}-\mathrm{G} / 2$ and $\mathrm{R}_{3}=\mathrm{Fmag}+\mathrm{G}$. With these values, the required friction coefficient results to be around $\mu=0.41[=200 /(580-90)]$. This still is acceptable; especially as slipping in this case does not mean that the robot is about to fall.

\section{3) Risk of dropping from the ceiling}

The risk of dropping from the ceiling of the tank can be neglected. Two wheel units with a capacity of holding $580 \mathrm{~N}$ each have to withstand a gravity force G of only $180 \mathrm{~N}$. 


\section{Child robot}

The child robot is already manufactured and works well (Fig. 13). Its mass is $0.8 \mathrm{~kg}$, plus $1.2 \mathrm{~kg}$ payload (inspection sensor $0.3 \mathrm{~kg}$ and cable $0.9 \mathrm{~kg}$ ) $-2 \mathrm{~kg}$ in total.

The cable is connected directly to the control unit on the ground, thus the child robot can also operate without the mother robot. The magnetic attraction force was measured to $4 * 22 \mathrm{~N}=88 \mathrm{~N}$ on the thin ground $(0.7 \mathrm{~mm})$ and $4 * 40 \mathrm{~N}=$ $160 \mathrm{~N}$ on the thick one $(1.5 \mathrm{~mm})$. So its security against falling can be estimated to be around Sfall $=4.4(=88 / 20)$.

With the finally chosen actuator, a speed of approximately $30 \mathrm{~m} / \mathrm{min}$ could be achieved.
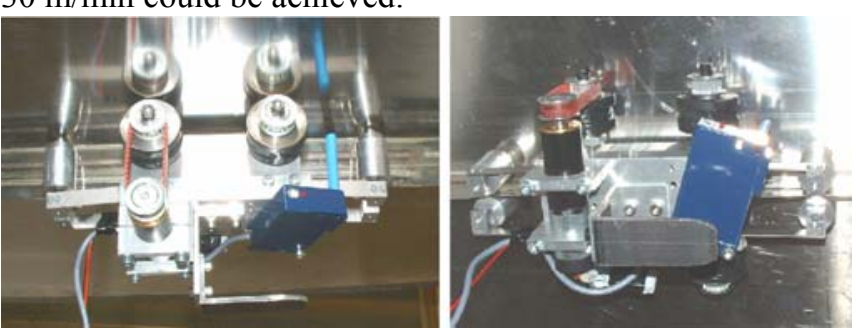

Fig 13: Prototype for the child robot

\section{CONCLUSION AND FUTURE PROSPECTS}

The robotic system presented in this work includes many innovative aspects like the fact that two climbing robots in mother-child structure are used - providing significant advantages in terms of speed increase and mass reduction.

Within the child robot, the main innovative idea is to use the structure as a rail to allow a pure mechanical guidance. On the mother robot, the main innovations are to use many light magnetic wheels in parallel to obtain higher forces on thin surfaces, to design them mass-optimized in a conic shape, with high inner diameter to place the actuators inside to save space, and to build a structure with active linear elements for passing difficult obstacles.

The design is almost finished. The most important parts have already been tested, work well and are very close to the final product. A nearly autonomous control strategy for a uniformly structured environment (as it was described by our industrial partner) has been proposed,

Not only for this application can the idea to separate the problem into two robots be a promising solution. Also for other tasks (surveillance, cleaning, repairing) there is an increasing demand for extremely lightweight and small robots - at a mass and size that is much smaller than it is feasible in complex structured climbing robots with high mobility. For all these tasks, using a more or less complex mother robot and a small, lightweight and simple child robot is a promising approach - with still a lot of variation potential considering the locomotion principles of both robots and the docking mechanism. For example, using a cable car for the mother robot could be a simple alternative for all applications, where the walls are mainly vertical, e.g. surveillance tasks on huge buildings.

\section{REFERENCES}

[1] W. Fischer, F. Tâche, R. Siegwart, Magnetic Wall Climbing Robot For Thin Surfaces With Specific Obstacles, Proceedings of the 6th International Conference on Field and Service Robotics, July 9-12 2007

[2] C. Balaguer, G. Virk, M. Armada, Robot Applications Against Gravity, Robotics \& Automation Magazine, IEEE, Volume 13, Issue 1, March 2006, pp. 5- 6

[3] H. Slocum, S. Awtar, J. Hart, Magnebots: Magnetic Wheels Based Overhead Transportation Concept, Conference paper from IFAC Mechatronics 2002 (Berkeley, Dec/2002)

[4] W. Guy, Magnetic Wheel, U.S. Patent 3,690,393, September 1972

[5] T. Sogi, Y. Kawaguchi, H. Morisaki, K. Ohkawa, N. Kai, H. Hayakawa, Inspection Robot for Spherical Storage Tanks, 26th Annual Conference of the IEEE Industrial Electronics Society, Volume 1, 22-28 Oct. 2000, pp. 393 - 398

[6] Y. Kawaguchi, I. Yoshida, H. Kurumatani, T. Kikuta, Y. Yamada, Internal Pipe Inspection Robot, Proceedings of the IEEE International Conference on Robotics and Automation, Volume 1, 21-27 May 1995, pp. $857-862$

[7] F. Tâche, W. Fischer, R. Siegwart, Adapted Magnetic Wheels for Robots Inspecting Narrow Pipes with Complex Shape, submitted for publication at 2007 IEEE/ASME International Conference on Advanced Intelligent Mechatronics, September 4-7, 2007

[8] T. Yukawa, H. Okano, S. Komatsubara, Mechanisms for the Movement of Piping Inspection Robot with Magnetic Elements, Proceedings of the IASTED International Conference on ROBOTICS AND APPLICATIONS, 2005, Cambridge (USA)

[9] J.C. Grieco, M. Prieto, M. Armada, P. Gonzalez de Santos, A Sixlegged Climbing Robot for High Payloads, Proceedings of the 1998 IEEE International Conference on Control Applications, Volume 1, 1 4 Sept. 1998 pp. $446-450$

[10] S. Hirose, H. Tsutsumitake, Disk Rover: A Wall-climbing Robot Using Permanent Magnetic Discs, Proceedings of the 1992 1EEE/RSJ International Conference on Intelligent Robots and Systems, Volume 3, July 7-10, 1992 pp. 2074 - 2079

[11] S. Weimin, J. Gu, S. Yanjun, Proposed Wall Climbing Robot with Permanent Magnetic Tracks for Inspecting Oil Tanks, International Conference on Mechatronics and Automation, Volume 4, 29 July-1 Aug. 2005 pp. 2072 - 2077

[12] S. Kitai, K. Tsuru, S. Hirose, The Proposal of Swarm Type Wall Climbing Robot System "Anchor Climber" - Design and Examination of the Adhering Mobile Unit, International Conference on Intelligent Robots and Systems, 2-6 Aug. 2005 Page(s):475 - 480

[13] X. Jizhong, A. Sadegh, M. Elliott, A. Calle, A. Persad, C. Ho Ming, Design of Mobile Robots with Wall Climbing Capability, International Conference on Advanced Intelligent Mechatronics, 2005 pp. 438 - 443

[14] R.T. Pack, J.L. Christopher Jr., K. Kawamura, A Rubbertuator-based Structure-climbing Inspection Robot, International Conference on Robotics and Automation, Volume 3, 20-25 April 1997 pp. 1869 1874

[15] D. Longo, G. Muscato, Alicia ${ }^{3}$ Climbing Robot: a Three-module Robot for Automatic Wall Inspection, Robotics \& Automation Magazine, IEEE, Volume 13, Issue 1, March 2006 , pp. 42- 50

[16] S. Yamamoto, Development of an Inspection Robot for Nuclear Power Planty", IEEE International Conference on Robotics and Automation, Volume 2, 12-14 May 1992 pp. 1559 - 1566

[17] R. Aracil, R.J. Saltaren, O. Reinoso, A Climbing Parallel Robot: $a$ Robot to Climb along Tubular and Metallic Structures, Robotics \& Automation Magazine, Volume 13, Issue 1, 2006, pp. 16- 22

[18] K. Autumn, A. Dittmore, D. Santos, M. Spenko, M. Cutkosky, Frictional Adhesion: a New Angle on Gecko Attachment”, J Exp Biol, 209 (18); pp. 3569-3579, 2006

[19] A. Asbeck, S. Kim, M. R. Cutkosky, W. Provancher and M. Lanzetta, Scaling Hard Vertical Surfaces with Compliant Microspine Arrays, The International Journal of Robotics Research, 2006; 25; 1165

[20] C. Balaguer, A. Gimenez, A.J. Huete, A.M. Sabatini, M. Topping, G. Bolmsjo, The MATS Robot: Service Climbing Robot for Personal Assistance, Robotics \& Automation Magazine, IEEE, Volume 13 Issue 1, March 2006, pp. 51- 58 